\section{Post intubation tracheal stenosis in children}

\author{
Marco Caruselli,1 Mirco Amici,2 \\ Dario Galante, ${ }^{3}$ Olivier Paut, ${ }^{1}$ \\ Giovanni De Francisci,4 Laura Carboni5
}

1Anesthesia and Intensive Care Unit, La Timone Children's Hospital, Marseille, France; ${ }^{2}$ Anesthesia and Intensive Care Unit, Salesi Children's Hospital, Ancona, Italy; ${ }^{3}$ Department of Anesthesia and Intensive Care, University Hospital

Ospedali Riuniti, Foggia, Italy

4Department of Anesthesiology and Intensive Care, Gemelli Hospital, Catholic University of the Sacred Heart, Rome, Italy; ${ }^{5}$ Anesthesia and Intensive Care Unit, Burlo Garofalo Children's Hospital, Trieste, Italy

\section{Abstract}

Many authors have reported that tracheal stenosis is a complication that can follow tracheal intubation in both adults and children. The symptoms, when they do appear, can be confused with asthma, with subsequent treatment providing only mild and inconsistent relief. We report here the case of an 8 year old girl admitted to our hospital for whooping cough that was not responding to therapy.

\section{Introduction}

Many authors have reported that tracheal stenosis is a complication that can follow tracheal intubation in both adults and children, with an variable incidence between 0.6 to $11.38 \% .1,2$

The main risk factors associated with tracheal stenosis are, the time spent intubated, tissue hypoperfusion and intubation related trauma. 3,4

The symptoms can appear immediately after extubation, or sometimes days later and can include tachypnoea, difficulty in breathing, noisy breathing when asleep, tracheal tug and distended jugular veins in deep inspiration.

Chest X-Rays generally look normal, although sometimes show signs of lung hyperinflation.

The symptoms, when they do appear, can be confused with asthma, with subsequent treatment providing only mild and inconsistent relief and in some cases, inappropriate treatment can persist for many years.

\section{Case Report}

We would like to report the case of an 8 year old girl admitted in hospital for whooping cough that was not responding to therapy.

Her past medical history revealed that after birth at 34 weeks she was admitted to a NICU for neonatal respiratory distress, where she was intubated with a $3.5 \mathrm{~mm}$ uncuffed tube and ventilated for 10 days without apparent complications.

Once she was discharged she experienced signs of stridor until she was 3 months old.

The symptoms then progressively improved until they completely disappeared.

We also found that the patient had two or three episodes per year of difficulty in breathing, which was successfully treated and controlled with inhaled Salbutamol.

From the age of 6 , the patient did not have any respiratory problems other than occasional noisy breathing.

The whooping cough winch she was admitted for, was present constantly for the previous 6 months and was worsening. We performed spirometry that showed anomalies during the inspiratory and expiratory phases despite the use of beta 2 agonists.

Her chest X-Ray revealed hyperinflated lungs without any pleuroparenchimal lesions.

After a week of treatment with beclometasone and fluticasone/salmeterol, the patient was not showing any signs of improvement in terms of symptoms or spirometry.

Thus, taking into account her past medical history with a prolonged tracheal intubation, we decided to perform a bronchoscopy.

The bronchoscopy was performed under sedation and showed severe subglottic stenosis due to a concentric membrane that caused a narrowing of the trachea, but below the trachea the respiratory tree was found to be normal (Figure 1).

After removing the tracheal membrane, the patient was asymptomatic without any more signs of respiratory distress.

\section{Discussion and Conclusions}

Several authors have reported tracheal stenosis post intubation since the ' 70 , some other even when the intubation was only for a short period of time. 5,6

It has been demonstrated that the trauma during intubation, situations of hypoxia or hypoperfusion, cuffed endotracheal tubes and the length of the intubation period are all risk factors for tracheal stenosis.

The cause suggested by many athors is a tracheal localized ischemic necrosis and an excessive granulation tissue formation with a
Correspondence: Marco Caruselli, Anesthesia and Intensive Care Unit, La Timone Children's Hospital, 264 Rue Saint Pierre, 13385 Marseille, France.

Tel.: +33.491.380.000.

E-mail:m.caruselli@gmail.com

Key words: tracheal intubation, subglottic stenosis, asthma, broncoscopy.

Contributions: the authors contributed equally.

Conflict of interests: the authors declare no potential conflict of interests.

Received for publication: 24 May 2014.

Revision received: 21 November 2014.

Accepted for publication: 21 November 2014.

This work is licensed under a Creative Commons Attribution NonCommercial 3.0 License (CC BYNC 3.0).

(C) Copyright M. Caruselli et al., 2014

Licensee PAGEPress, Italy

Pediatric Reports 2014; 6:5491

doi:10.4081/pr.2014.5491

process of scar contracture. ${ }^{7-10}$

Usually, for adult patients admitted and ventilated in Intensive Care, an early tracheostomy is performed to avoid the consequences of a prolonged intubation.

However, controversy still remains as to the correct timing of when to perform tracheostomy in children, considering that children usually need to remain intubated for longer than adults.

In neonatal intensive care it's traditionally recommended to utilize the uncuffed endotracheal tubes because in children younger of 8 years the narrowest point of the airway is at the level of the circumferential cricoid cartilage. Furthermore, to intubate with the cuffed tracheal tube it's necessary to utilize the tube of smaller diameter and that creates large increases in airway resistance during mechanical ventilation. ${ }^{11}$

The experience of Black et al. on 2953 pediatric patients intubed by uncuffed tubes in intensive care unit reports that none of the patients had clinical symptoms of acquired subglottic stenosis. 12

For against other Authors showed that the use of cuffed endotracheal tubes in pediatric patients not associated with an increased risk of subglottic stenosis and morevover avoid the unwanted aspirations of gastric contents. ${ }^{13-15}$

Although the positive experience of many authors, the described case show that also the uncuffed endotracheal tube can create the conditions for the damage of tracheal mucosa.

The damage sometimes can be caused by the maneuvers of intubation but more likely is 


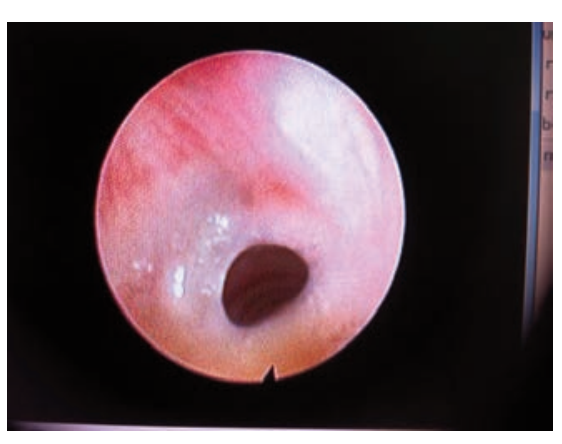

Figure 1. The bronchoscopy shows severe subglottic stenosis; below the trachea the respiratory tree was found to be normal.

due to the movement of the tube within the trachea particularly during the weaning of mechanical ventilation period, when the child make the movements and probably also the endotracheal tube have some movements who causes damage of tracheal mucosa. That can create the condition favorable for future tracheal stenosis.

It is very important to take an accurate past medical history in children who have specific respiratory problems such as moderate respiratory difficulty, noisy breathing, frequent cough or abnormal results in the spirometry with a poor response to the therapies.

When there is a history of endotracheal intubation, even for a short period of time (therefore to be considered not only during an intensive care admission but also if the child underwent intubation during general anesthe- sia); it is recommended to perform a bronchoscopy in order to exclude a tracheal stenosis.

\section{References}

1. Rodriguez H, Cuestas G, Botto H, et al. Post-intubation subglottic stenosis in children. Diagnosis, treatment and prevention of moderate and severe stenosis. Acta Otorrinolaringol Esp 2013;5:339-44.

2. Schweiger C, Marostica PJ, Smith MM, et al. Incidence of postintubation subglottic stenosis in children: prospective study. J Laringol Otol 2013;4:1049-54.

3. Liu H, Chen JC, Holinger LD, GonzalesCrussi F. Histopathologic fundamentals of acquired laryngeal stenosis. Pediatr Pathol Lab Med 1995;5:655-77.

4. Kus LH, Sklar MC, Neghandi J, et al. Corrosion casting of the subglottis following endotracheal tube intubation injury: a pilot study in Yorkshire piglets. $\mathrm{J}$ Otolaringol Head Neck Surg 2013;14:4252.

5. Yang KL. Tracheal stenosis after a brief intubation. Anaesth Analg 1995;80:625-7.

6. Wei JL, Bond J. Management and prevention of endotracheal intubation injury in neonates Curr Opin Otolaringol Head Neck Surg 2011;4:1049-54.

7. Dzhafarov CM, Israfilova SB, Rustamade UC. Diagnosis and treatment of postintu- bation tracheal stenosis. Klin Khir 2012;42-5.

8. Zias N, Chroneou A, Tabba MK, et al. Post tracheostomy and post intubation tracheal stenosis; report of 31 cases and review of the literature. BMC Pulm Med 2008;8:18.

9. Wain JC. Post intubation tracheal stenosis. Chest Surg Clin N Am 2003;13:231-46

10. Viveiros F, Gomes J, Oliveira A, et al. Topical application of mitomycin-C as an adjuvant treatment to bronchoscopic procedures in post-intubation tracheal stenosis. Rev Port Pneumol 2013;19:276-80.

11. Fine GF, Borland LM. The future of cuffed endotracheal tube. Pediatr Anaesth 2004; 14:38-42.

12. Black AE, Hatch DJ, Nauth-Misir N. Complications of nasotracheal intubation in neonates, infants and children: a review of 4 years experience in a children's hospital. Br J Anesth 1990;65:461-7.

13. Newth CJL, Rachman B, Patel N, et al. The use of cuffed versus uncuffed endotracheal tubes in pediatric intensive care. J Pediatr 2004;144:333-7.

14. Khim HH, Corddry DM, Kettrick RG, et al. Comparison of cuffed and uncuffed endotracheal tubes in young children during general anesthesia. Anesthesiology 1997;86:627-31.

15. Weiss M, Dullenkopf A, Fischer JE, et al. Prospective randomized controlled multicenter trial of cuffed or uncuffed endotracheal tubes in small children. BJA 2009;103:867-73. 